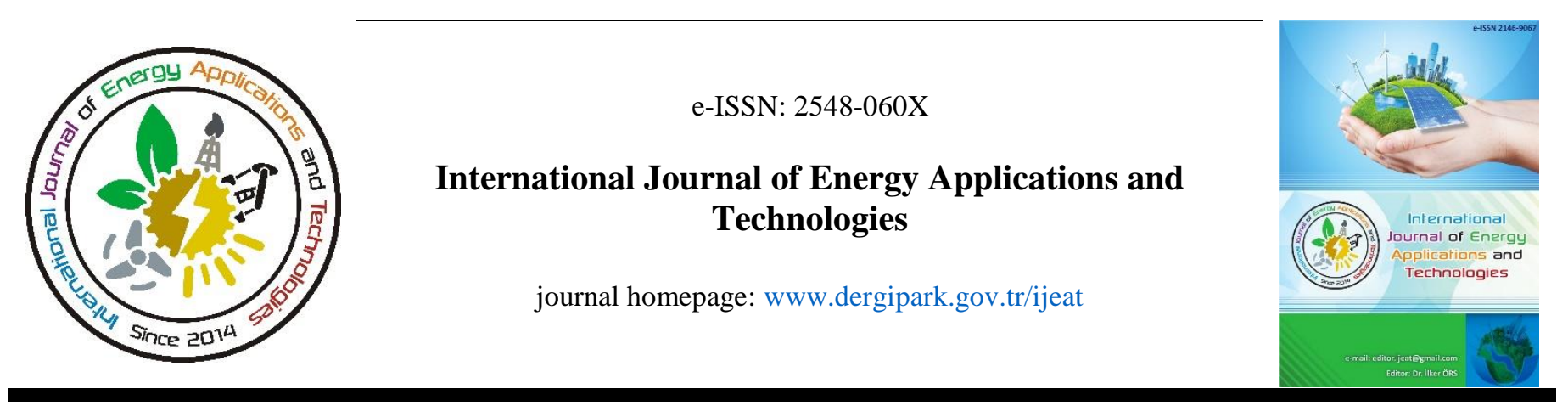

Original Research Article

\title{
Thermodynamic analysis of an ejector cooling system using R123 as refrigerant under different working conditions
}

hosted by JourkinalPark

\author{
M. Emin Tolü, Dilek Nur Özen,, ${ }^{2,}$ Uğur Köklü ${ }^{1}$ \\ ${ }^{1}$ Karamanoğlu Mehmetbey University, Mechanical Engineering Department, Karaman, Turkey \\ ${ }^{2}$ Necmettin Erbakan University, Mechanical Engineering Department, Konya, Turkey
}

\begin{abstract}
ARTICLE INFO
* Corresponding author

dnozen@konya.edu.tr

Received May 25, 2018

Accepted May 30, 2018

Published by Editorial Board Members of IJEAT

(C) This article is distributed by Turk Journal Park System under the $\mathrm{CC} 4.0$ terms and conditions.
\end{abstract}

doi:10.31593/ijeat.427229

\begin{abstract}
Meeting the energy demand and reducing high energy costs are becoming more and more essential for mankind. Concordantly, increasing scientific studies are trying to provide new techniques and solutions every day. In the area of refrigeration technology, which is the cause of a considerable part of the energy consumption, very significant studies are being done to increase energy efficiency. Ejector cooling technology, which is supposed to be able to replace conventional cooling systems, is an area of research that attracts the attention of researchers and that various researches are being carried out on them. In this study, theoretical performance analysis of an ejector cooling system that is using R123 as refrigerant and designed according to the constant area model has done. In the cooling system, the ejector is considered as the substitute of the compressor. The theoretical analysis of the system was carried out by using a computer program which is being used for modelling and simulation. All the data belong to the thermodynamic properties of R123 refrigerant were processed to the program. By using this data in the prepared program, it is possible to simulate desired values according to different situations and conditions. Thus, the effects of using R123 refrigerant on the coefficient of performance (COP) of the cooling system under various operating conditions are examined and the findings are presented in graphs.
\end{abstract}

Keywords: Ejector, COP, Entrainment ratio, Temperature, Simulation, Cooling, Refrigerant

\section{Introduction}

In recent years, many research facilities and companies are making studies on the purpose of using energy more efficiently. For cooling machines, this means that Coefficient of Performance (COP) of these machines have to be increased and one way to increase COP of cooling machines is using wasted heat in cogeneration cycles. Refrigeration cycles can use this wasted heat in absorption cycles or by the use of ejectors [1].

There are lots of studies on the ejector cooling systems presented in the existing literature. Yapic1 and Ersoy [2] presented optimized results for R123 in a study which they investigated the performance characteristics of the ejector refrigeration system based on the constant area ejector flow model. They concluded that the optimum COP and area ratio determined by using the constant area flow model in this study are greater than the values in the literature that were obtained at the same working temperatures for the constant pressure flow model. Chen et al., [3] investigated recent developments in the ejector refrigeration technologies and categorized the studies in several topics including; refrigerant selection, mathematical modelling and numerical simulation, geometric optimization, operating conditions and combinations with other refrigeration systems. Yilmaz et al., [4] presented a theoretical approach to the ejector cooling system. They reported that using an ejector instead of an expansion element reduces the load on the compressor and 
increases the system performance. Yang and Zhao [5] studied on the thermodynamic analysis of a combined power-ejector refrigeration cycle using zeotropic mixtures. The presented cogeneration system consists of an organic Rankine cycle and an ejector refrigeration cycle. They used various working fluids, including pure working fluids, R245fa and R600a, and zeotropic mixtures, R245fa/R600a. The results show that the mixtures generate more refrigeration than pure working fluids. Besagni et al., [6] presented an overall literature review on ejector refrigeration systems and working fluids. They analyzed ejector technology, refrigerant properties and their effects on ejector performance, with a focus on past, present and future trends. The review is configured as four sections. First section designated for the description of the ejector technology. Second section includes a detailed description of the refrigerant properties and their effects on ejector performance. In the third section, a review about the main jet refrigeration cycle is proposed and the ejector refrigeration systems are categorized. Finally, in the last section, an overview on ejector technologies with the relationship among the working fluids and the ejector performance are presented. Özen and Tolu [7] made a theoretical study and analyzed the effects of various refrigerants on the performance of an ejector refrigeration system. They used twelve different refrigerants and the results show that the refrigerant with the highest COP value is R717, and the refrigerant with the lowest COP value is R114. Ma et al., [8] presented an elaborate study on thermodynamic modelling method of an ejector for ejector refrigeration system. In this model, the primary flow in the ejector was assumed to fan out from the nozzle without mixing with the secondary flow in a certain downstream distance, so that a hypothetical throat was formed where the secondary flow reached the sound speed. They developed empirical correlations of the hypothetical throat area to aid further modelling.

Thermodynamic analysis of an ejector system using R123 as the working fluid carried out in this study. In the presented system, the ejector is used instead of the compressor. Observing and presenting the changes occurred on the entrainment ratio (w) and COP of the system at the different working temperatures of evaporator, condenser and generator was the main aim of this study. Besides, a simulation program based on a mathematical model was developed to analyse the thermodynamic performance of the ejector cooling systems using different refrigerants.

\section{Materials and Methods}

\subsection{Ejector refrigeration system}

An ejector refrigeration system consists of a generator, a condenser, an evaporator, an expansion valve, a pump and an ejector as shown in the Fig. 1. Refrigeration cycle is shown in the Fig.2.

Cooling and power cycles constituting the system are described as below;

The power cycle;

- In process 6-1 of Fig. 2, heat is transferred from the heat source to the working fluid. The working fluid enters the heat source as compressed liquid and is assumed to be saturated steam when leaving from the heat source.

- In process 1-b, the pressure drops with the expansion of the primary flow through the motive nozzle and the secondary flow is drawn to the secondary nozzle from the vacuum effect. The two flows merge at point $b$ '.

- In process b'-4, the kinetic energy of the mixture is converted to static pressure by a diffuser element, and the pressure of the working fluid is increased to the pressure of the condenser, which is reduced in advance. Thus, the ejector operates as a compressor.

- In process 4-5, the working fluid passes through the condenser at a constant pressure and the senses and latent heat on it are transferred to the surroundings. It is assumed that the working fluid is separated from the condenser as saturated liquid.

- In process 5-6, the cycle is completed by passing through the fluid pump to raise the pressure of the working fluid back to the pressure of the heat source.

- The refrigeration cycle;

- In process 7-2 of Fig. 2, heat is transferred to the working fluid as it passes through the evaporator and the fluid is transformed from wet steam to saturated steam.

- In process 2-b, the secondary flow from the evaporator to the secondary nozzle is taken at the same time to ejector by the vacuum effect to mix with the supersonic flow which is also known the primary flow and then follows the previously mentioned mixing path in the power cycle.

- In process 5-7, the cycle is completed by passing through the fluid expansion valve to lower the pressure of the working fluid back to the evaporator pressure.

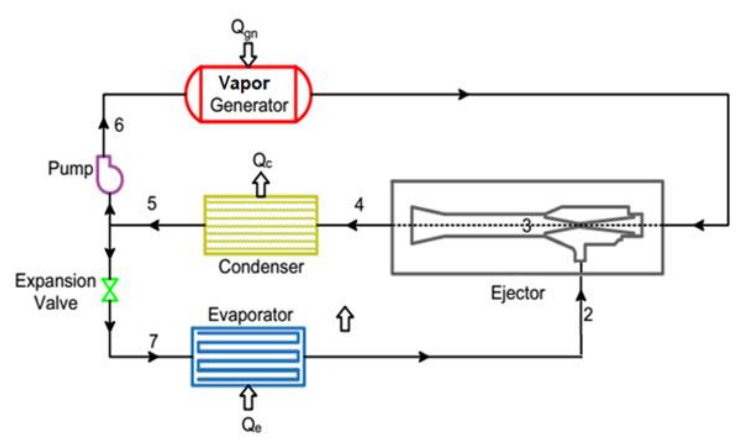

Figure 1. Schematic display of the ejector cooling system 


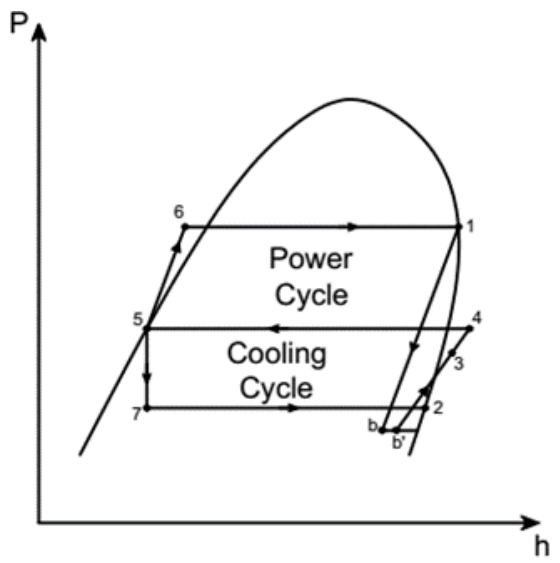

Figure 2. P-h diagram of the ejector cooling system

The study of Yapic1 et al. [9] which we used as a reference work, used a constant area model for ejector. Hence, constant area model for ejector was chosen in this study too. Fig. 3 shows the schematic display of the constant area model.

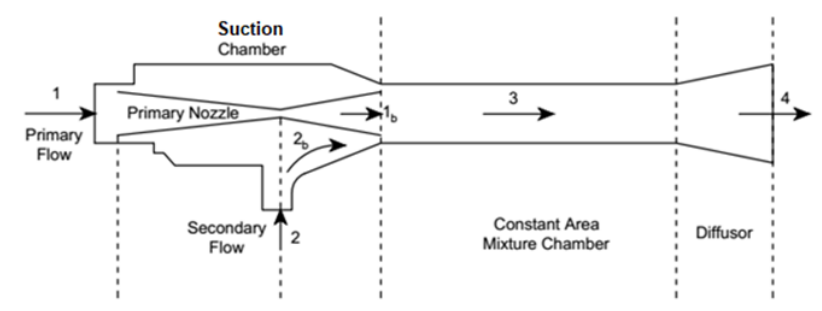

Figure 3. An ejector designed by using the constant area model

\subsection{Mathematical model}

A mathematical model for the thermodynamic analysis of the ejector cooling system in different refrigerants has been established. The theory of the ejector cooling system is based on the law of conservation of energy and momentum. It has been accepted that there is no pressure loss in system elements and the model is at a steady state. Following the above assumptions, the governing equations are formulated for the elements of the ejector cooling system. Numerical algorithm for the model is given in Fig. 4. A computer added calculation and modelling program has been used for the numerical model. In the algorithm of the mathematical model given in Fig. 3.1., the values entered in the program, the estimated values and the verification method of the estimates are indicated.

Used equations at the calculations of primer nozzle are given at equations 1-4:

$$
\begin{gathered}
\mathrm{h}_{1 \mathrm{~b}}=\left(1-\eta_{\mathrm{pr}}\right) \cdot \mathrm{h}_{1}+\eta_{\mathrm{pr}} \cdot \mathrm{h}_{1 \mathrm{~b}, \mathrm{~s}} \\
\eta_{\mathrm{pr}}=\frac{\mathrm{h}_{1}-\mathrm{h}_{1 \mathrm{~b}}}{\mathrm{~h}_{1}-\mathrm{h}_{1 \mathrm{~b}, \mathrm{~s}}} \\
\mathrm{u}_{1 \mathrm{~b}}=\left[2 \cdot\left(\mathrm{h}_{1}-\mathrm{h}_{1 \mathrm{~b}}\right)\right]^{1 / 2}
\end{gathered}
$$

$$
\mathrm{a}_{1 \mathrm{~b}}=\frac{\mathrm{v}_{1 \mathrm{~b}}}{\left[\mathrm{u}_{1 \mathrm{~b}} \cdot(1+\mathrm{w})\right]}
$$

The entrainment ratio $(w)$ defined as the ratio of mass flow rate of the secondary flow $\left(\dot{\mathrm{m}}_{\mathrm{s}}\right)$ to the primary flow $\left(\dot{\mathrm{m}}_{\mathrm{p}}\right)$ is displayed as [10]:

$$
\mathrm{w}=\frac{\dot{\mathrm{m}}_{\mathrm{sn}}}{\dot{\mathrm{m}}_{\mathrm{pr}}}
$$

The equations for the secondary nozzle are given with equations 6-9:

$$
\begin{gathered}
\mathrm{h}_{2 \mathrm{~b}}=\left(1-\eta_{\mathrm{sn}}\right) \cdot \mathrm{h}_{2}+\eta_{\mathrm{sn}} \cdot \mathrm{h}_{2 \mathrm{~b}, \mathrm{~s}} \\
\eta_{\mathrm{sn}}=\frac{\mathrm{h}_{2}-\mathrm{h}_{2 \mathrm{~b}}}{\mathrm{~h}_{2}-\mathrm{h}_{2 \mathrm{~b}, \mathrm{~s}}} \\
\mathrm{u}_{2 \mathrm{~b}}=\left[2 \cdot\left(\mathrm{h}_{2}-\mathrm{h}_{2 \mathrm{~b}}\right)\right]^{1 / 2} \\
\mathrm{a}_{2 \mathrm{~b}}=\left[\frac{v_{2 b}}{\mathrm{u}_{2 b}}\right] \cdot \frac{\mathrm{w}}{(1+\mathrm{w})}
\end{gathered}
$$

The used equations for the mixing chamber are shown below as:

$$
\begin{aligned}
\mathrm{h}_{3} & =\left(\frac{1}{1+\mathrm{w}}\right) \cdot\left(\mathrm{h}_{1}+\mathrm{w} \cdot \mathrm{h}_{2}\right)-\left(\mathrm{u}_{3}^{2} / 2\right) \\
\mathrm{u}_{3} & =\mathrm{P}_{\mathrm{b}} \cdot\left(\mathrm{a}_{1 \mathrm{~b}}+\mathrm{a}_{2 \mathrm{~b}}\right)+\left[\frac{1}{(1+\mathrm{w})} \cdot \mathrm{u}_{1 \mathrm{~b}}\right] \\
& +\left[\frac{\mathrm{w}}{(1+\mathrm{w})} \cdot \mathrm{u}_{2 \mathrm{~b}}\right]-\left(\mathrm{P}_{3} \cdot \mathrm{a}_{3}\right) \\
& \mathrm{a}_{3}=\left(\mathrm{a}_{1 \mathrm{~b}}+\mathrm{a}_{2 \mathrm{~b}}\right)
\end{aligned}
$$

The equations for the diffuser are shown at equations 13-14:

$$
\begin{aligned}
& \mathrm{h}_{4}=\left[\frac{\mathrm{h}_{1}+\left(\mathrm{w} \cdot \mathrm{h}_{2}\right)}{(1+\mathrm{w})}\right] \\
& \mathrm{h}_{4, \mathrm{~s}}=\eta_{\mathrm{d}} \cdot\left(\mathrm{h}_{4}-\mathrm{h}_{3}\right)+\mathrm{h}_{3}
\end{aligned}
$$

To find the area of ratio $\left(A_{r}\right)$ following equation must be used:

$$
A_{r}=\frac{a_{1 b}}{a_{3}}=\frac{a_{1 b}}{\left(a_{1 b}+a_{2 b}\right)}
$$

Finally, the coefficient of performance (COP) of the system is calculated with the equation below:

$$
\mathrm{COP}=\frac{\dot{\mathrm{Q}}_{\mathrm{e}}}{\dot{\mathrm{Q}}_{\mathrm{gn}}+\dot{\mathrm{W}}_{\mathrm{p}}}
$$



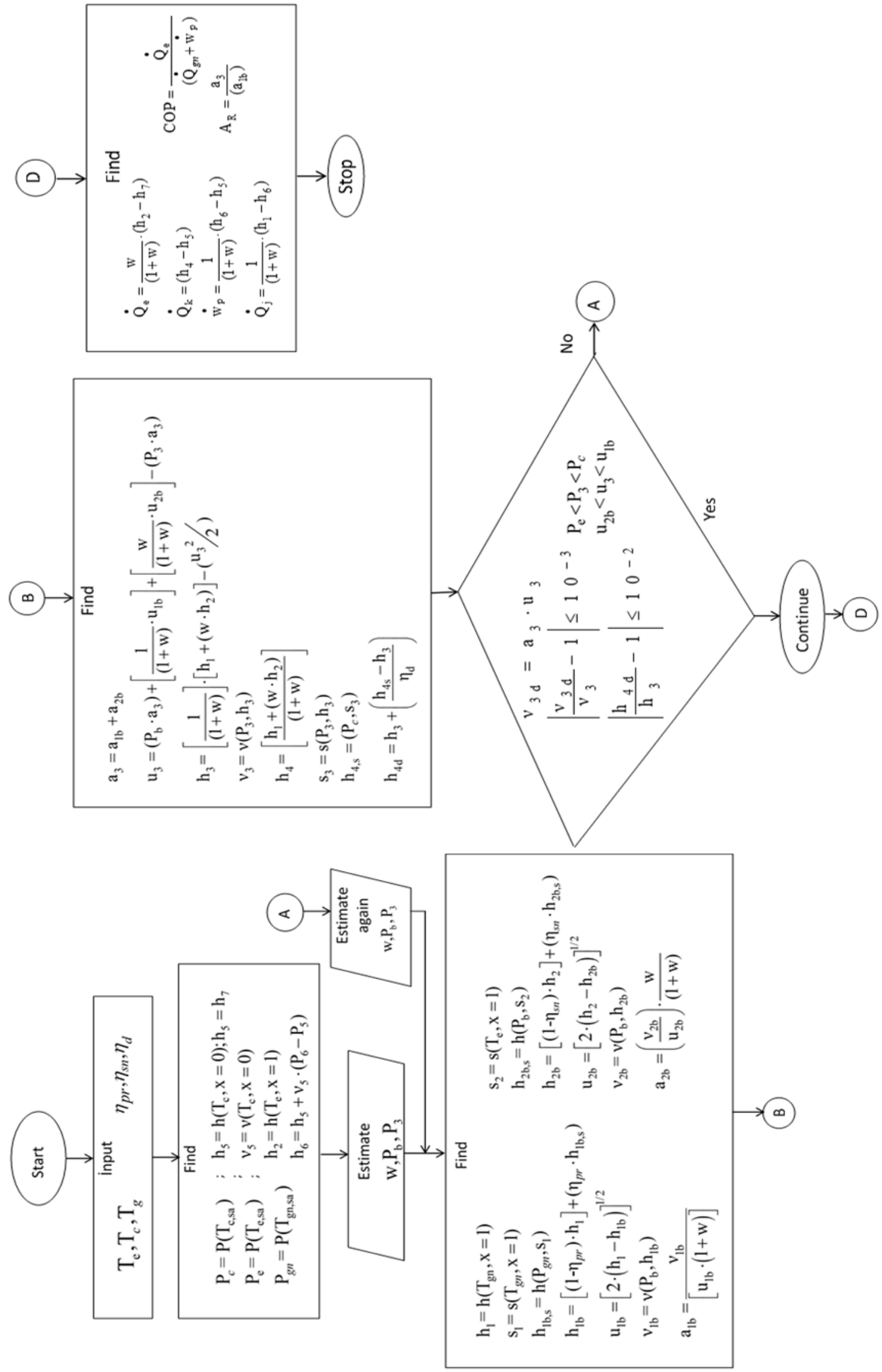

Figure 4. Algorithm of the numerical model 


\section{Results and Discussion}

The data obtained from the mathematical model are compared to the data from reference study of Yapic1 et al. [9]. Results are graphically displayed in Fig. 5. This method is used to validate the mathematical model and evaluate the accuracy of the simulation program. Effects of the changes at the temperatures of evaporator, generator and condenser on the entrainment ratio and the COP were investigated for R123 refrigerant. At the final stage, the effects of changes at the temperature of the condenser on the optimum ejector area ratio is examined. According to Fig.5, the minimum difference observed between the theoretical and experimental results is $0.1 \%$ and the maximum difference observed is $6.5 \%$ while working temperature of evaporator is between 8.9$12.6^{\circ} \mathrm{C}$. If the working temperature of evaporator is more than $12.6^{\circ} \mathrm{C}$, this difference increases parallel to the increase at the evaporator temperature. The maximum difference is $18.9 \%$ for the evaporator temperature of $15.1{ }^{\circ} \mathrm{C}$. It can be seen that; steadier results are possible at the evaporator temperature below $13{ }^{\circ} \mathrm{C}$ according to the simulation program.

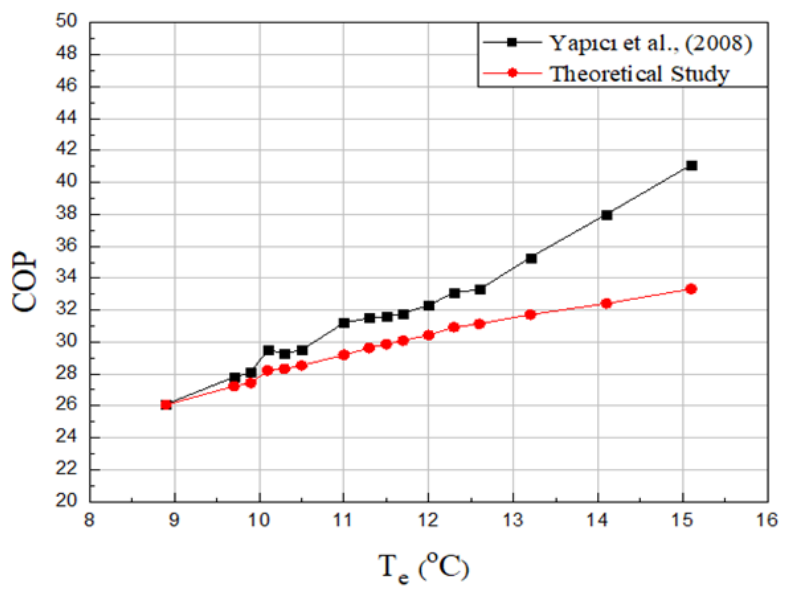

Figure 5. Comparison of the values of the theoretical study with the experimental values obtained by Yap1c1 et al., [9]

\subsection{The effects of the evaporator temperature on the COP and the entrainment ratio}

The effects of the evaporator temperature on the COP values and entrainment ratio can be seen in Fig. 6 and Fig. 7 respectively.

It can be seen that as the evaporator temperature increases the COP of R123 and the entrainment ratio increases too. Below the value of $0{ }^{\circ} \mathrm{C}$ for the evaporator temperature, the changes observed are negligible but as the evaporator temperature increases, increase rate of COP and $\mathrm{w}$ is also gets higher. For the entrainment ratio it can be said that; as the evaporator temperature increases, evaporator pressure also increases. This increases directly effects the entrainment ratio and causes it to increase. The obtained data are in resemblance with the data obtained from the study of Yapici and Ersoy [2]. As a result, it has been observed that, changes at the evaporator temperature effects the system performance significantly.

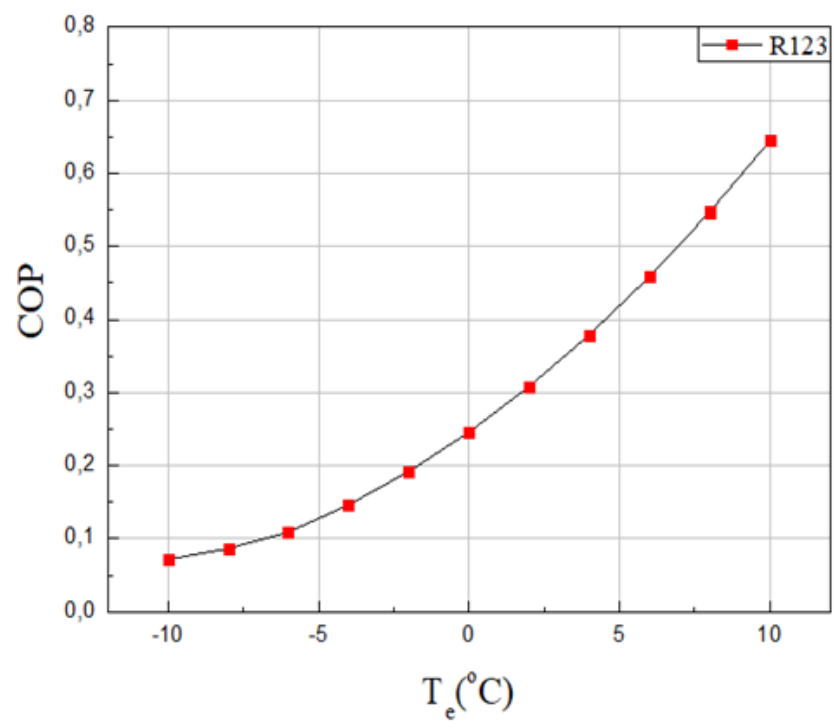

Figure 6. Graphical display of the correlation between $\mathrm{T}_{\mathrm{e}}$ and $\mathrm{COP}$

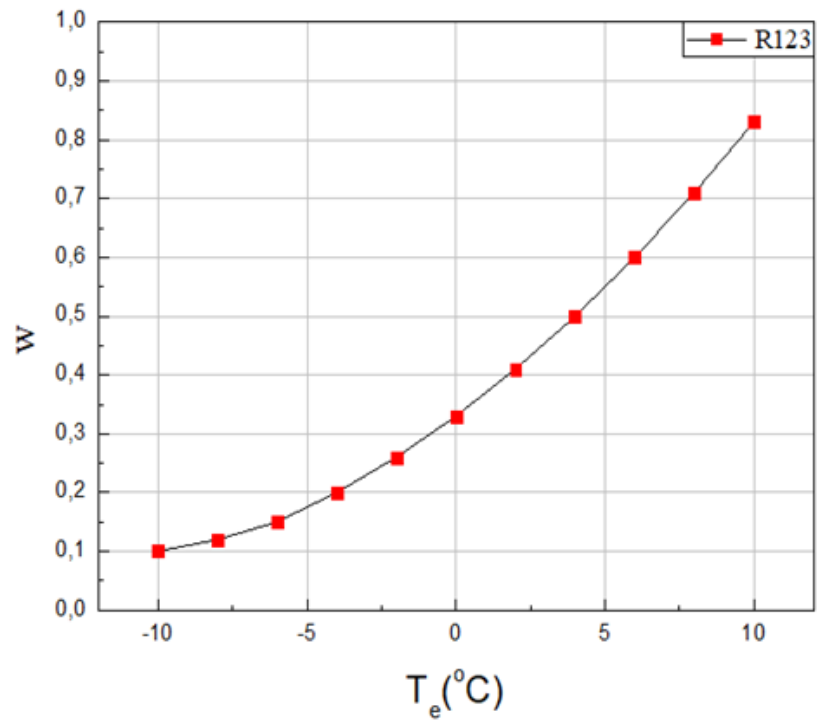

Figure 7. Graphical display of the correlation between $T_{e}$ and $\mathrm{w}$

\subsection{The Effects of the generator temperature on the COP and the entrainment ratio}

The changes at the COP values and the entrainment ratio due to the changes of the evaporator temperature is presented in Fig. 8 and Fig. 9 respectively.

As shown in Fig. 8 and Fig. 9, changes occurred at the generator temperature effect the COP and entrainment ratio similar to the changes at the evaporator temperature. Increase occurred at the generator temperature increases both COP values of the system and entrainment ratio. At the higher 
temperature values than $75^{\circ} \mathrm{C}$ for the generator, calculated changes on the COP and entrainment ratio are significant. Below that temperature there are no serious changes on these values. For the entrainment ratio, it can be said that, the increase at the generator temperature also increases the pressure difference between the evaporator and the outlet of the nozzle. This causes an increase on the entrainment ratio. These results are also in resemblance with the results obtained from the study of Yapıc1 and Ersoy 2005 [2]. By means of these results, it can be determined that generator temperature has a respectable effect on the performance of the ejector cooling system.

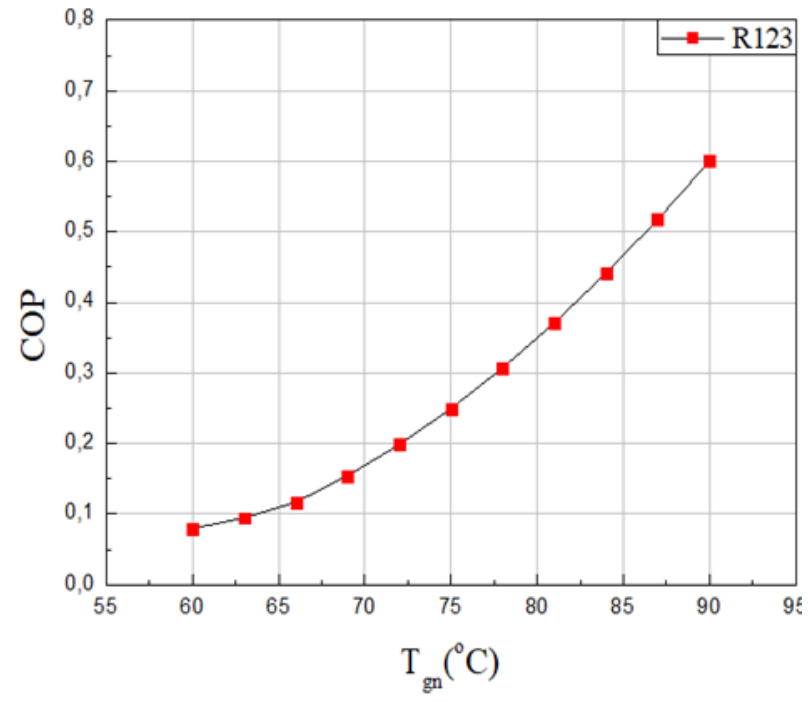

Figure 8. Graphical display of the correlation between $\mathrm{T}_{\mathrm{gn}}$ and COP

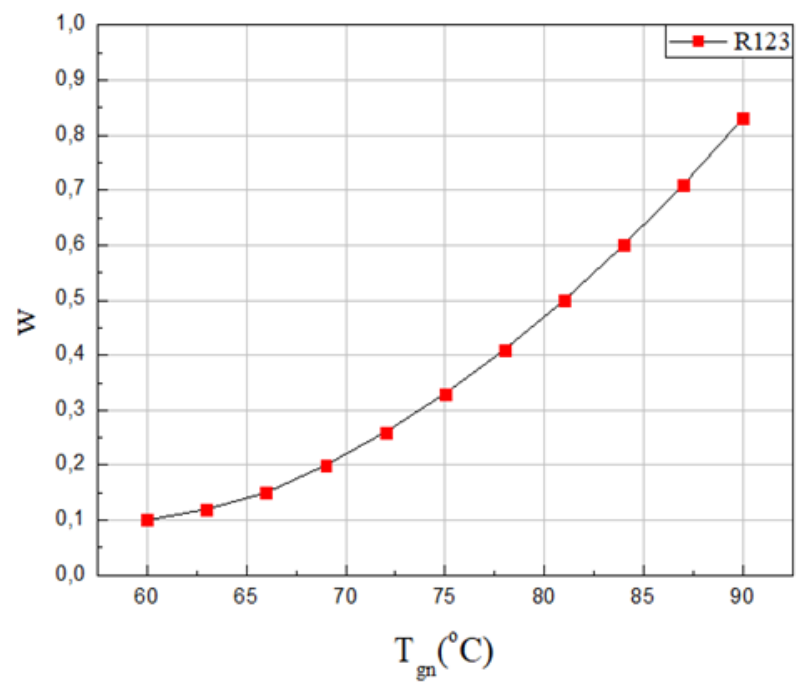

Figure 9. Graphical display of the correlation between $\mathrm{T}_{\mathrm{gn}}$ and $\mathrm{W}$

3.3. The effects of the condenser temperature on the COP and the entrainment ratio

The effects of the changes at the temperature of the condenser on the COP values and entrainment ratio is graphically displayed in Fig. 10 and Fig. 11 respectively.
It can be seen that the changes occurred at the condenser temperature influence the $\mathrm{COP}$ and entrainment ratio different from evaporator temperature and generator temperature. COP and entrainment ratio decreases as the condenser temperature increases. The COP values of R123 and the entrainment ratio gradually decreases between the condenser temperature of $30-40{ }^{\circ} \mathrm{C}$. At the greater condenser temperatures than $40{ }^{\circ} \mathrm{C}$, changes observed on the COP and entrainment ratio are minor. These results are also in resemblance with the results of study of Yapic1 and Ersoy [2]. As a result, it has been observed that, changes at the condenser temperature effects the system performance significantly.

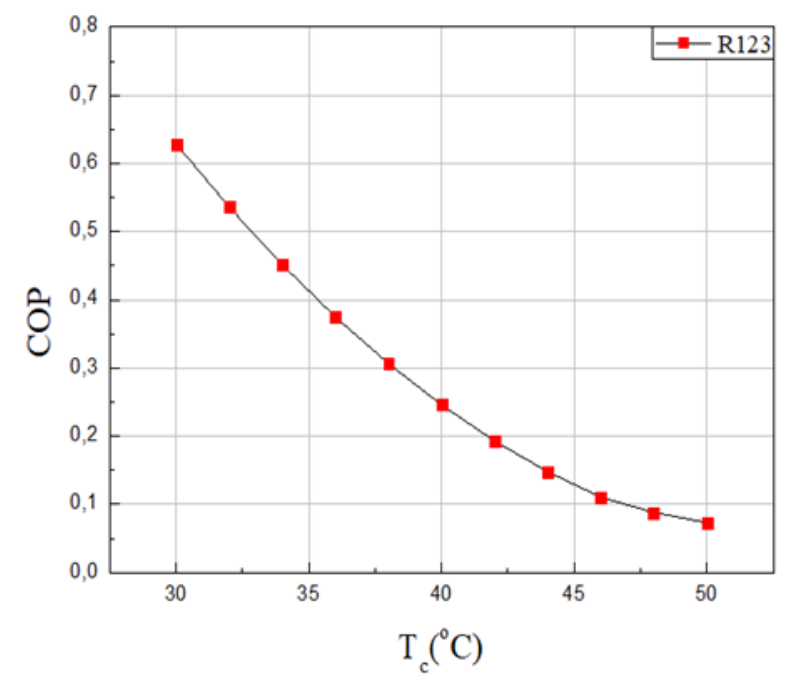

Figure 10. Graphical display of the correlation between

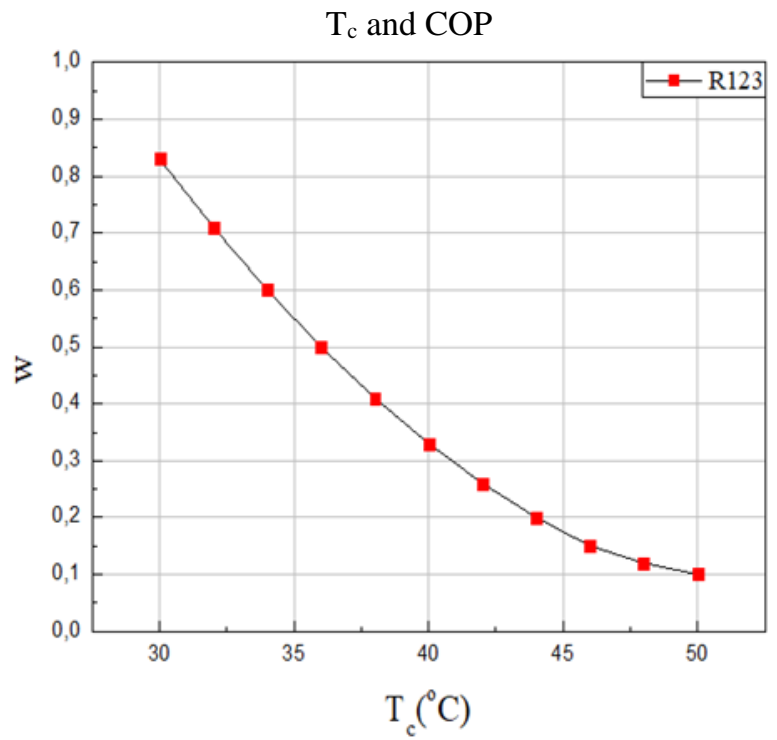

Figure 11. Graphical display of the correlation between $\mathrm{T}_{\mathrm{c}}$ and $\mathrm{w}$

3.4. The effects of the condenser temperature on the optimum ejector area ratio (Ar)

The effects of condenser temperature on the optimum ejector area ratio is given in Fig. 12. 


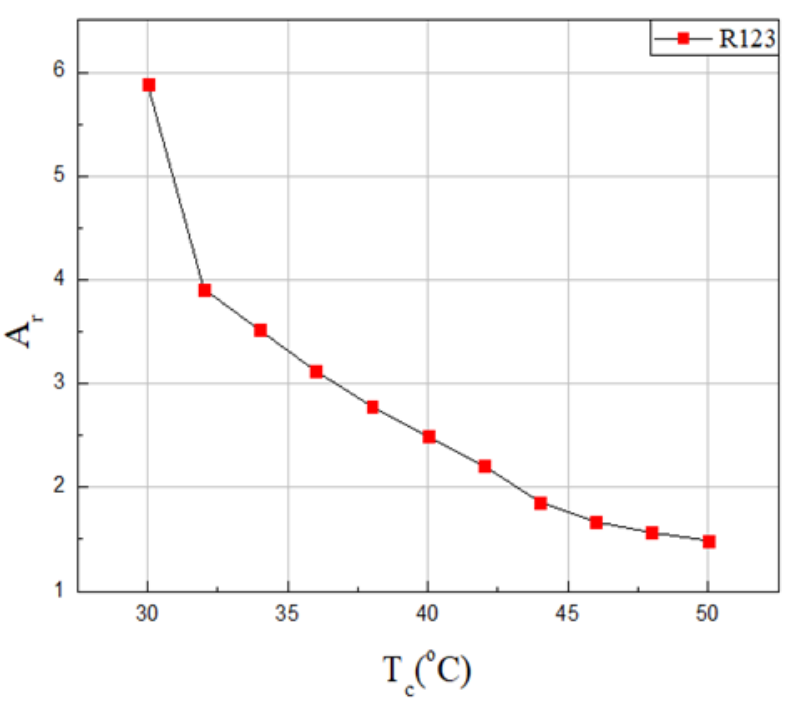

Figure 12. Graphical display of the correlation between $\mathrm{T}_{\mathrm{c}}$ and $\mathrm{A}_{\mathrm{r}}$

Fig. 12 shows that the optimum ejector area ratio decreases as the condenser temperature increases. An increase at the condenser temperature causes the primer fluid flow and the primer nozzle exit area to increase. Due to the increase on the primer fluid flow and the primer nozzle exit area, the optimum ejector area ratios decrease.

\section{Conclusion}

In this study, thermodynamic analysis of an ejector cooling system created with constant area model and using R123 as refrigerant, was performed. The changes occurred on the cooling performance coefficient and the entrainment ratio depending on the evaporator, generator and condenser temperatures in the cooling system were investigated. Also the effects of the condenser temperature on the optimum ejector area ratio were was examined. It has been determined that as the temperatures of the evaporator and the generator increases, the COP values of the system and the entrainment ratio increases as well. It was observed that when the condenser temperature increases, the COP of the system and entrainment ratio decreases as an adverse effect.

All of the results and data gathered are presented graphically. It has been decided that the mathematical model and the simulation program that were prepared for this study are reliable enough for future studies and projects.

\section{References}

[1] Carrillo, J. E., de La Flor, F. S., \& Lissén, J. S., 2017, "Thermodynamic comparison of ejector cooling cycles. Ejector characterisation by means of entrainment ratio and compression efficiency", International Journal of Refrigeration, 74, 371-384.

[2] Yapic1, R., \& Ersoy, H. K., 2005, "Performance characteristics of the ejector refrigeration system based on the constant area ejector flow model", Energy conversion and management, 46(18-19), 3117-3135.

[3] Chen, X., Omer, S., Worall, M., \& Riffat, S., 2013, "Recent developments in ejector refrigeration technologies", Renewable and Sustainable Energy Reviews, 19, 629-651.

[4] Yilmaz, F., Selbaş, R., \& Üçgül, İ., 2014, “Ejektörlü Soğutma Sisteminin Teorik Olarak İncelenmesi”, SDÜ Yekarum e-Dergi, 2(2).

[5] Yang, X., \& Zhao, L., 2015, “Thermodynamic analysis of a combined power and ejector refrigeration cycle using zeotropic mixtures", Energy Procedia, 75, 1033-1036.

[6] Besagni, G., Mereu, R., \& Inzoli, F., 2016, "Ejector refrigeration: a comprehensive review", Renewable and Sustainable Energy Reviews, 53, 373-407.

[7] Özen, D.N., Tolu, M.E., 2016, "Theoretical analysis of a cooling system with an ejector for different refrigerants," in IEESE8, p. 1198-1202.

[8] Ma, Z., Bao, H., \& Roskilly, A. P., 2017, "Thermodynamic modelling and parameter determination of ejector for ejection refrigeration systems", International Journal of Refrigeration, 75, 117 128.

[9] Yapıc1, R., Ersoy, H. K., Aktoprakoğlu, A., Halkacı, H. S., \& Yiğit, O., 2008, "Experimental determination of the optimum performance of ejector refrigeration system depending on ejector area ratio", International Journal of Refrigeration, 31(7), 1183-1189.

[10] Chen, J., Jarall, S., Havtun, H., \& Palm, B., 2015, "A review on versatile ejector applications in refrigeration systems", Renewable and Sustainable Energy Reviews, 49, 67-90.

\begin{tabular}{|ll|ll|}
\hline \multicolumn{2}{|c|}{ Nomenclature } & & \multicolumn{2}{c|}{ Index } \\
\hline $\mathrm{COP}$ & Coefficient of Performance & $\mathrm{e}$ & Evaporator \\
$\mathrm{T}$ & Temperature, ${ }^{\circ} \mathrm{C}$ & $\mathrm{c}$ & Condenser \\
$\mathrm{P}$ & Pressure, $\mathrm{kPa}$ & $\mathrm{d}$ & Diffusor \\
$\mathrm{a}$ & Area, $\mathrm{m}^{2}$ & $\mathrm{f}$ & Fluid State \\
$\mathrm{Ar}$ & Area Ratio & $\mathrm{g}$ & Gaseous State \\
$\mathrm{w}$ & Flow Rate & $\mathrm{gn}$ & Generator \\
$\mathrm{h}$ & Enthalpy, $\mathrm{kJ} / \mathrm{kg}$ & $\mathrm{pr}$ & Primer Nozzle \\
$\mathrm{s}$ & Entropy, $\mathrm{kJ} / \mathrm{kg} . \mathrm{K}$ & $\mathrm{s}$ & Isentropic \\
$\mathrm{v}$ & Specific Volume, $\mathrm{m}^{3} / \mathrm{kg}$ & $\mathrm{sa}$ & Saturation \\
$\eta$ & Efficiency & $\mathrm{sn}$ & Seconder Nozzle \\
$\dot{Q}$ & Thermal Capacity, $\mathrm{kW}$ & & \\
$\dot{m}$ & Mass Flow, kg/s & & \\
$\mathrm{u}$ & Velocity of Flow, $\mathrm{m} / \mathrm{s}$ & & \\
$\dot{W}$ & Power of the Pump, $\mathrm{kW}$ & & \\
$\eta$ & Efficiency & & \\
\hline
\end{tabular}

